\title{
Hepatitis A vaccination during an outbreak among gay men in Montréal, Canada, 1995-1997
}

\author{
R Allard, J Beauchemin, L Bédard, R Dion, M Tremblay, J Carsley
}

\begin{abstract}
Study objective-To evaluate an intervention designed to curtail an outbreak of hepatitis A among gay men, especially the young and sexually active, by promoting their free vaccination.

Design-The study analysed routine passive surveillance data, carried out questionnaire and serological surveys of vaccinees, and surveys among the target population in non-clinical venues. Setting and intervention-15000 free doses of hepatitis $A$ vaccine were made available through clinics with large gay clienteles, or at gay events, and advertised by various means, in Montréal, Canada, from August 1996 to November 1997. Simultaneous vaccination against hepatitis B (always free for gay men) was also encouraged.

Participants-Information was obtained from persons with the disease during the epidemic period, a sample of men requesting vaccination, and five community samples of gay men.

Main results-The outbreak involved 376 gay men and the vaccine was distributed to approximately 10000 . Vaccinees were older than cases, but had many sex partners and comprised more food handlers. Special vaccination clinics at gay events were well attended but did not reach more high risk men than regular medical venues. A self reported vaccine coverage of $49 \%$ was achieved, but $26 \%$ of vaccinees already had anti-HAV antibodies. Disease incidence declined rapidly during the campaign.

Conclusions-The intervention nearly tripled self reported hepatitis A vaccine coverage but its late start precludes proving that it caused the subsequent drop in incidence. However, it also increased hepatitis $B$ vaccination and it is believed it improved links between gay men, public health, clinicians and community groups. (F Epidemiol Community Health 2001;55:251-256)
\end{abstract}

Outbreaks of hepatitis A in gay communities have occurred frequently in recent decades, ${ }^{1-15}$ facilitated by oral-anal contacts. ${ }^{25} 6$ In Montréal, Canada, with over 1800000 inhabitants and a well established "gay village", there was an outbreak of more than 500 known cases over a two year period from 1990 to 1992, mostly among homosexual and bisexual (henceforth "gay") men, ${ }^{15}$ resulting in one death. In November 1994 the number of reported cases of hepatitis A among gay men in
Montréal again began to increase rapidly. Health promotion messages widely distributed to the gay community and health care providers during the winter of 1995 had no detectable impact on the evolution of the outbreak (fig 1).

Although vaccination programmes have been used with success to stop hepatitis A transmission in closed communities where most cases were among children, ${ }^{16-20}$ their efficacy is unknown in an open adult community. Nevertheless, with the collaboration of local community clinics, selected private medical clinics and gay community groups, the Montréal Regional Health Board launched a vaccination programme in August 1996 in an effort to end the outbreak.

\section{Methods}

As required by law, cases of hepatitis A were reported to public health authorities either by laboratories or by physicians, and could be confirmed either serologically (anti-HAV IgM positive, $95 \%$ of cases), or clinically (increase in hepatic enzymes or jaundice, plus a link with a laboratory confirmed case), through a routine interview by a public health nurse with the physician or the patient, or both. The interview also elicited information about possible sources of infection.

The main objective of the intervention (called VaccinAction against hepatitis $A$ ) was to vaccinate as many gay men as possible in the younger (and more sexually active) age group living in Montreal's "gay village"(a small neighbourhood with a concentration of gay residents and gay oriented businesses), so as to shorten the course of the current epidemic and prevent further epidemics. The secondary objective was to increase the vaccine coverage against hepatitis B in the same group. Ten community clinics, 15 private medical clinics and some 40 solo practitioners, all of them in Montréal, were asked to vaccinate eligible men and all agreed to participate. They had been chosen among 250 active providers of free hepatitis $\mathrm{B}$ vaccine to gay men. Any gay male Montrealer holding a Quebec government health insurance card (available to all permanent residents) was eligible to receive the free hepatitis A and B vaccines. In practice, vaccinators could infer sexual orientation from the request for the vaccine, without inquiry, and no proof of residency in Montréal was required.

Publicity for the intervention took several forms. (1) A mock postcard was inserted in a widely read, free gay magazine, in July and August of 1996 and 1997, before Gay Pride week. (2) Advertisements appeared regularly in 
nine periodicals widely read by the gay community. (3) Articles by, or interviews with programme personnel appeared in some of these same periodicals. (4) Postcards, flyers and posters were distributed in gay bars and saunas, and among gay community organisations. (5) Promotional material was sent directly to individuals on the mailing lists of some community organisations. (6) Organisations for younger gay men were targeted especially to receive written and oral information (group and individual meetings) about the programme. (7) Information and/or promotional material was regularly mailed to various professionals and organisations. (8) Promotional material was distributed at several AIDS fund raising events (marches and parties) and other gay oriented events (film festival and dances).

The campaign was launched by a press conference on 28 July 1996, resulting in widespread media coverage. Special vaccination clinics were held on 4 August 1996, as part of Gay Pride Week and on 2 November 1996, as a Halloween event. Otherwise, the vaccine was available during vaccinators' regular business hours.

Our initial intent was to provide only the first dose of hepatitis A vaccine free, this being thought sufficient to interrupt the outbreak. However, in February 1997, with 9500 doses distributed, 5500 remaining and demand waning, the second dose was also made free. This bonus was used to reactivate the publicity campaign, but there was no effort to recall individually recipients of the first dose. Demand picked up and remained stable until all 15000 doses had been distributed, by November 1997.

We distributed 3010 numbered questionnaires to 38 vaccinators, to be answered anonymously by vaccinees from the beginning of the campaign until the vaccinator's questionnaire supply was exhausted. They were either returned to the vaccinator's receptionist or mailed to the investigators in a pre-stamped and pre-addressed envelope. There were 11 questions, on sociodemographics, sex partners, perceptions of the campaign, the vaccine and the vaccination procedure. A similar but shorter questionnaire was administered during the special vaccination clinics. The purpose of this non-random survey was to verify that the target population was being reached and to reorient the campaign if needed.

Among the vaccinators, eight public and private clinics agreed to obtain blood specimens for hepatitis A serology from a predetermined number of consecutive vaccinees answering the questionnaire (600 in all). They were chosen because they were expected to be the largest vaccinators, and the Health Board already had a close working relationship with them. For these, a specimen tube bearing the same number as the questionnaire was provided.

We also conducted a series of surveys (fig 2) on perceptions of the campaign and vaccine coverage in the gay community, between

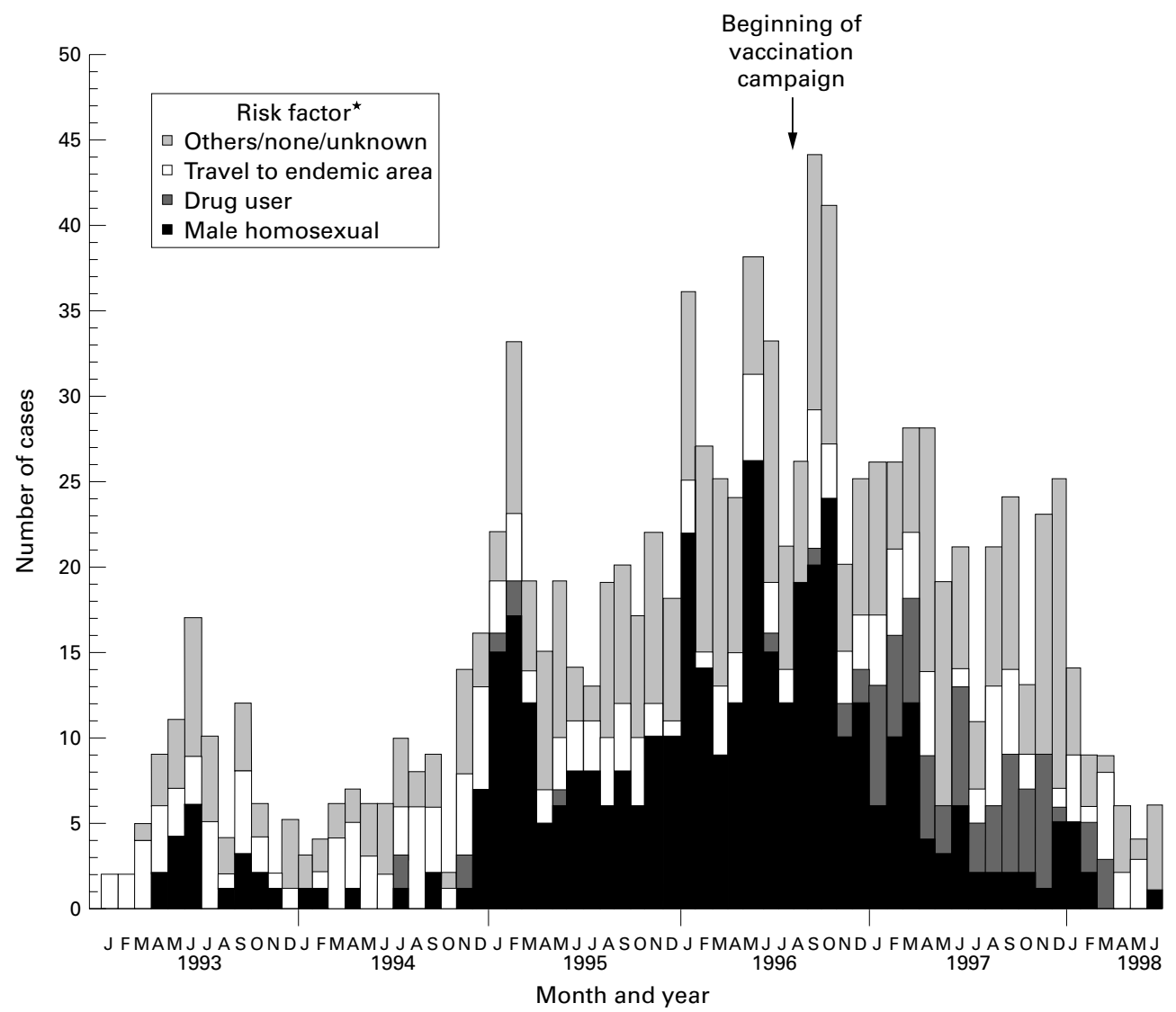

Figure 1 Epidemic curve for hepatitis A, by month of reporting and risk factor, Island of Montreal, fanuary 1993 to fune 1998. Source: Montréal Regional Public Health Department. ${ }^{\star B e t w e e n ~ t w o ~ a n d ~ s e v e n ~ w e e k s ~ b e f o r e ~ d i s e a s e ~ o n s e t . ~}$ 


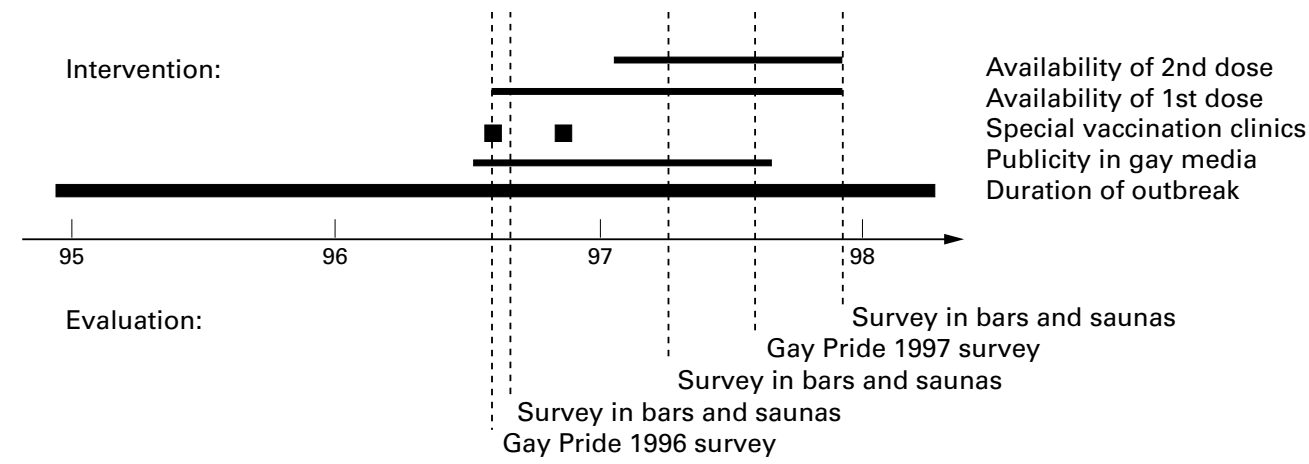

Figure 2 Timeline of the main events around the outbreak, the intervention and its evaluation.

August 1996 and November 1997, in two types of venues: Gay Pride celebrations and gay bars and saunas. Baseline and one year follow up surveys were conducted on Gay Pride days. The respondents were recruited systematically and without reference to vaccination status, with a predetermined sampling fraction, by trained, well identified interviewers, who kept track of the number of men they approached, for response rate estimation. The three surveys among patrons of 10 gay bars and three saunas located mainly in the gay village used a similar sampling method. Bars favoured by younger gay men were especially targeted.

The evaluation of the campaign was approved by the Research Ethics Committee of the Montreal General Hospital. Written informed consent was obtained from participants in the serological survey of vaccinees.

\section{Results}

DESCRIPTIVE EPIDEMIOLOGY OF THE OUTBREAK The reported incidence of hepatitis A for the island of Montréal (equivalent to the Health Board region), which had been 4.6/100 000 in 1993 and 5.0 in 1994, rose to 12.5 in 1995, 19.5 in 1996 and 14.3 in 1997 . This increase affected men aged between 20 and 39 years, among whom the incidence reached a maximum of 85.6 per 100 000. A large proportion of cases lived in or near the gay village, and information on risk factors (available for $87 \%$
Rate/100 000 men per year

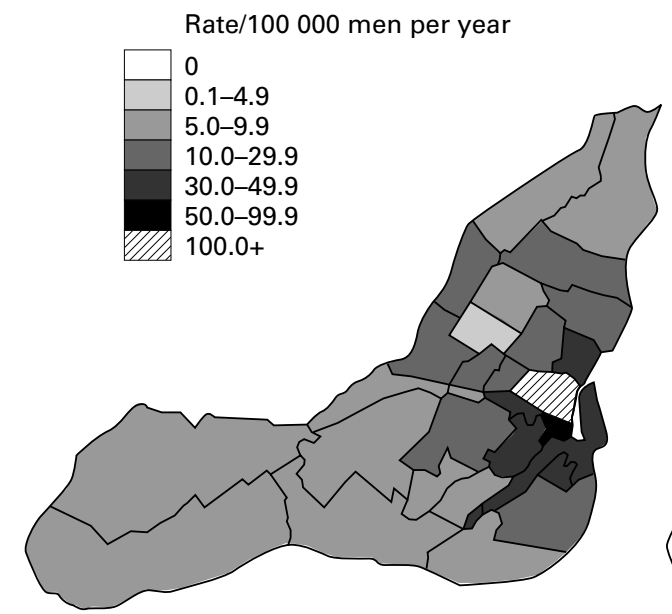

of cases) indicated an increase in the proportion of cases among gay men, which began in December 1994 and ended in February 1998 (fig 1).

There were 376 cases reported among gay men, of whom 331 had had sex with other men between two and seven weeks before the beginning of the illness. Their average age was 33.4 years (range 18 to 59 years). Almost $13 \%$ of these cases were hospitalised, for a median duration of four days. Eight per cent of the 139 cases among gay men with known occupation occurred in food handlers or barmen.

Figure 3 shows the geographical distribution of notified incidence rates of hepatitis A among men. Incidence rates were higher in or around the gay village (corresponding roughly to the black areas, especially that on the right panel).

CHARACTERISTICS OF VACCINEES

Fifty five per cent of questionnaires for vaccinees were answered during the first month of the campaign, $85 \%$ during the first three months and $100 \%$ during the first six months. Of 3010 questionnaires distributed to vaccinators, 235 had not been used by the time the study ended. The overall response rate is thus $71 \%$ (1980 of 2775 ).

Table 1 presents the principal characteristics of vaccinee respondents. Canada was the country of origin for $89 \% ; 4 \%$ came from Europe and $3 \%$ from Central or South America. The age range was 18 to 75 years.

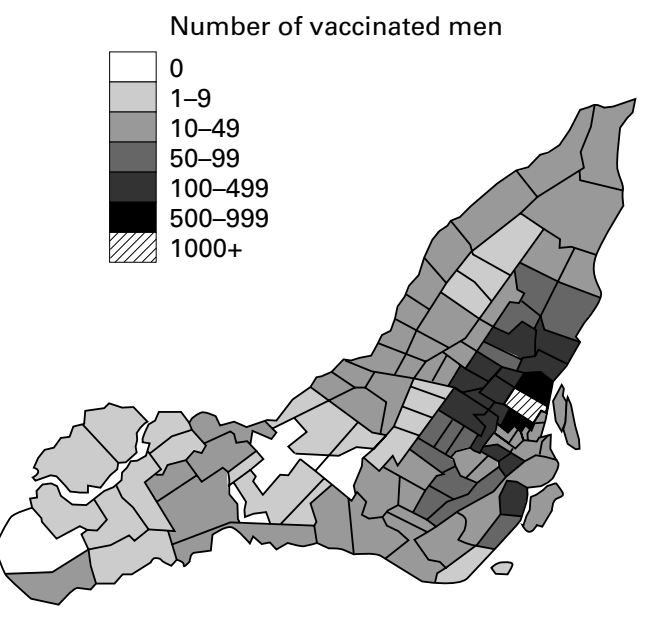

Figure 3 Geographical distributions of reported hepatitis A incidence rates among men, Island of Montreal, November 1994 to February 1998, and of numbers of vaccinated men, August 1996 to November 1997. 
Table 1 Caracteristics of vaccinees, by vaccinator or special event

\begin{tabular}{llllc}
\hline Characteristics & $\begin{array}{l}\text { Gay Pride 1996 } \\
(n=496)\end{array}$ & $\begin{array}{l}\text { Halloween 1996 } \\
(n=231)\end{array}$ & $\begin{array}{l}\text { Community or private } \\
\text { medical clinics } \\
(n=1253)\end{array}$ & Total $(n=1980)$ \\
\hline Mean age (y) & 38.2 & 37.6 & 36.3 & 36.9 \\
Median age (y) & 37.0 & 36.0 & 35.0 & 36.0 \\
Mean number of partners & 10.1 & 8.7 & 8.3 & 8.8 \\
Median number of partners & 4.0 & 3.0 & 3.0 & 3.0 \\
Montréal residents & $84 \%(385 / 459)$ & $84 \%(186 / 222)$ & $91 \%(1031 / 1127)$ & $88 \%(1598 / 1808)$ \\
Sex with other men & $98 \%(477 / 484)$ & $97 \%(222 / 227)$ & $98 \%(1133 / 1155)$ & $98 \%(1830 / 1867)$ \\
Canadian born & $89 \%(442 / 494)$ & $90 \%(207 / 231)$ & $89 \%(1030 / 1158)$ & $89 \%(1679 / 1883)$ \\
Food handler & $20 \%(84 / 424)$ & $16 \%(35 / 225)$ & $17 \%(166 / 953)$ & $18 \%(285 / 1572)$ \\
\hline
\end{tabular}

*Over previous six months. Includes respondents without partners.

Compared with notified cases, a lower proportion of vaccinees were less than 30 years old $(23 \% v 29 \%)$ and a higher proportion were 40 or over $(32 \% v 16 \%)$. Food handlers made up $18 \%$ of vaccinees, compared with $8 \%$ of cases.

Of respondents who wrote they knew their hepatitis A immunisation status, $6 \%$ had already received a dose of vaccine. This proportion varied little by age. However, among these, $45 \%$ (35 of 80 ) gave a date prior to vaccine licensure in Canada, which suggests confusion with hepatitis $B$ vaccine. Thus we estimate that of the 15000 doses, at least 9187 $(9500 \times(1-0.06 \times 0.55))$ were given to persons who had not already received any hepatitis A vaccine. Figure 3 shows that the geographical distribution of vaccinated men closely follows that of cases.

SEROLOGICAL STATUS OF VACCINEES

Of the 600 collection tubes distributed for the serological survey of vaccinees, the 125 sent to one vaccinator remained essentially unused, and 353 were returned full by the other vaccinators. The blood samples were tested for total antibodies (IgM and IgG, measured together) against the hepatitis A virus, and 26\% (93 of 353) were found positive. Thus, we estimate that of the persons vaccinated, at least 6798 $(9187 \times 0.74)$ were susceptible to the disease when immunised during the campaign.

Two personal characteristics were significantly associated with positivity. The first was country of birth: $50 \%$ (15 of 30 ) of subjects born outside of Canada were positive, while $22 \%$ (52 of 231) of those born in Canada were. The other was age: $8 \%$ ( 7 of 83 ) of subjects less than 30 years old were positive, $17 \%$ (14 of 81 ) of those between 30 and $34,27 \%$ (19 of 69$)$ of those between 35 and 39, and 46\% (46 of 99) of those 40 or over. Logistic regression showed that these two associations were independent: in the same model, the odds ratio for HAV seropositivity among subjects born outside of Canada was 6.24 (95\% confidence intervals $2.59,15.03)$ and the odds ratio per year of age was 1.09 (95\% confidence intervals 1.06, 1.13).

PERCEPTIONS OF THE CAMPAIGN AND VACCINE COVERAGE IN THE TARGET COMMUNITY

Response rates in the surveys about perceptions of the campaign and vaccine coverage on Gay Pride days 1996 and 1997 were $81 \%$ and $86 \%$, giving 425 respondents, and those to the three surveys in bars and saunas were $68 \%$, $76 \%$ and $75 \%$, giving 697 respondents. In the
KEY POINTS

- An intervention promoting vaccination against hepatitis A among gay men demonstrably increased self reported vaccine coverage in this group.

- One quarter of gay men without a history of hepatitis $\mathrm{A}$ and requesting vaccination against it already had anti-HAV antibodies.

- The campaign achieved a vaccine coverage between $20 \%$ and $41 \%$ among susceptible gay men.

- Satisfaction with the vaccination campaign was high, except for the second dose of vaccine not being free.

- Pre-immunisation serological screening of gay men who are older or born in endemic countries may be cost efficient.

first survey, $92 \%$ of Gay Pride respondents, and $90 \%$ of those aged less than 25 years, were aware of the VaccinAction campaign. Nearly a month into the campaign, $93 \%$ had heard about it, but only $86 \%$ of men aged less than 25 had. Over time, campaign awareness remained high but did not increase: by campaign's end, $88 \%$ of respondents recalled having heard about it, but still only $81 \%$ of those aged less than 25 years had. Respondents learned of the campaign mainly through gay media $(30 \%)$, newspapers $(18 \%)$, television or radio $(17 \%)$, and friends (14\%). Overall, $89 \%$ knew that the first dose of vaccine was free.

Approval was high: $91 \%$ of those aware of the campaign said they agreed entirely with it and another $7 \%$ mostly agreed. The reason most often given was the vaccine being free and easily accessible. That the campaign had been initiated by "government" with community involvement was also appreciated, giving gay men a sense of recognition. However, some $6 \%$ thought the campaign would stigmatise gay men.

Table 2 presents the self reported vaccine coverage. There is a clear upward trend for both vaccines and all doses, but especially for hepatitis A vaccine. Some relevant results are not in the table: Among respondents with four or more sex partners in the previous six months, reported first dose coverage against hepatitis A was $56 \%$, compared with $44 \%$ among respondents with three or fewer partners. However, the coverage was only $33 \%$ in respondents aged less than 25 years compared with $52 \%$ in the others, and similarly for hepatitis B. 
Table 2 Self reported vaccine coverage at gay venues, by time, vaccine and dose

\begin{tabular}{lllll}
\hline Survey & $\begin{array}{l}\text { Hepatitis } A \\
\text { first dose }\end{array}$ & $\begin{array}{l}\text { Hepatitis } A \\
\text { complete }\end{array}$ & $\begin{array}{l}\text { Hepatitis } B \\
\text { first dose }\end{array}$ & $\begin{array}{l}\text { Hepatitis } B \\
\text { complete }\end{array}$ \\
\hline $\begin{array}{l}\text { 4 August } 1996 \\
\begin{array}{l}\text { Gay Pride } \\
(\mathrm{n}=196)\end{array}\end{array}$ & $17 \%( \pm 5.3)^{\star}$ & not asked & not asked & not asked \\
$\begin{array}{l}23-27 \text { August } 1996 \\
\text { Bars and saunas } \\
(\mathrm{n}=190)\end{array}$ & $22 \%( \pm 5.9)$ & $8 \%( \pm 3.9)$ & $36 \%( \pm 6.8)$ & $20 \%( \pm 5.7)$ \\
$\begin{array}{l}14-18 \text { March } 1997 \\
\text { Bars and saunas } \\
(\mathrm{n}=252)\end{array}$ & $43 \%( \pm 6.1)$ & $19 \%( \pm 4.8)$ & $46 \%( \pm 6.1)$ & $21 \%( \pm 5.0)$ \\
$\begin{array}{l}3 \text { August } 1997 \\
\begin{array}{l}\text { Gay Pride } \\
(\mathrm{n}=229)\end{array}\end{array}$ & $49 \%( \pm 6.5)$ & $34 \%( \pm 6.1)$ & not asked & not asked \\
$\begin{array}{l}21-25 \text { November } 1997 \\
\text { Bars and saunas } \\
(\mathrm{n}=255)\end{array}$ & $49 \%( \pm 6.1)$ & $39 \%( \pm 6.0)$ & $49 \%( \pm 6.1)$ & $25 \%( \pm 5.3)$ \\
\hline
\end{tabular}

$\star 95 \%$ confidence limits.

Uncertainty about the true size of the targeted community precludes precise calculation of the overall vaccine coverage. Our best estimate of the gay male population in Montréal is between 35000 and 40000 (Dr Robert S Remis, personal communication). What proportion of these men were susceptible to hepatitis A when the outbreak began is unknown. However, this proportion should not be larger than that observed among vaccinees, who selected themselves on the basis of perceived susceptibility, that is, 0.74 with a $95 \%$ confidence intervals of $0.69,0.78$. Applying these proportions to estimates of the gay male population in Montréal gives a minimum estimate of $24150(=0.69 \times 35000)$ susceptible gay men and a maximum of $31200(=0.78$ $\times 40000$ ). As for the numerator, at least 9500 and at most 15000 doses were used as first doses, $89 \%$ of them for Montrealers, $74 \%$ for susceptible men, giving a minimum of 6257 first doses and a maximum of 9879. A pessimistic estimate of the proportion of susceptible gay male Montréal residents immunised would thus be $20 \%$ (6257 of 31200 ) and an optimistic estimate $41 \%$ (9879 of 24150 ).

\section{Discussion}

The recruitment strategy yielded vaccinees who were almost all gay men, mostly living in the area of the outbreak. Twice as many vaccinees were over age 40 compared with cases, therefore having a relatively high probability of being already immune. Vaccination clinics at important gay events were well attended but did not help recruit higher risk men.

The proportion of vaccinees already antiHAV seropositive was low compared with that observed in the general population of the Montréal region ${ }^{21}$ or among gay men in San Francisco. ${ }^{22}$ However, as participating physicians had been instructed not to test (or vaccinate) gay men known to have had hepatitis A, our results suggest that a sizable proportion $(26 \%)$ of gay men who consider themselves susceptible to hepatitis A have in fact been infected, especially if they are older and/or born outside of Canada. Furthermore, testing for total anti-HAV antibodies is not routinely available in Montréal at present. It cost us \$C 12 per specimen and the vaccine costs $\$ 64$ for both doses. Roughly, then, prevaccination testing becomes cost effective when the proportion of those requesting the vaccine who have already been infected reaches $19 \%(\$ 12 \div \$ 64)$. Our results therefore suggest that preimmunisation testing of gay men born outside of Canada and/or aged 30 years or over might be cost effective, a result compatible with previous ones. ${ }^{23}$

Did the campaign shorten the outbreak? Conclusive evidence is difficult to provide for several reasons. (1) Vaccine coverage of susceptibles was not very high, although it is known only imprecisely. (2) Free vaccine became available relatively late in the outbreak, so that the decrease in hepatitis A cases which occurred shortly after the intervention began may be interpreted as the natural downslope at the end of the outbreak. (3) The small increase in hepatitis $\mathrm{B}$ vaccine coverage among gay men associated with the campaign was followed by a decrease in the yearly number of hepatitis B notifications among gay men in 1997 and 1998 compared with 1993 to 1996 . However, there was no detectable decrease in notifications during the campaign or in the months following it, so that the temporal association between the two events is not close, and the causal relation remains unclear.

Still, there is evidence of partial success: (1) Self reported vaccine coverage increased nearly threefold to $49 \%$ among gay men sampled, the largest gains occurring during the first eight months of the campaign. (2) Over a few months, the intervention reached at least 8500 $(9500 \times 0.89)$ gay men living mainly in and around Montréal's gay village, site of the majority of cases. (3) Vaccinees included a relatively high proportion of food handlers, with increased potential for disease transmission. (4) Since this outbreak in Montréal, Vancouver has also experienced a large outbreak among gay men. Using a similar intervention and evaluation strategy, a vaccine coverage comparable to ours was achieved, and a steep decline in the incidence of hepatitis A was observed three months later ( $\mathrm{P}$ Daly, 3rd National Immunization Conference, Calgary, Canada, 1998). Other evaluations of interventions similar to ours but more timely may provide a definitive answer about their effectiveness. However, we would rather see the question become moot as jurisdictions move toward routine hepatitis vaccination of high risk communities before outbreaks occur.

The authors thank the many community organisations, especially Divers-Cité, Action Séro-Zéro, AIDS Community Care of Montréal, and the owners of gay oriented establishments, for their invaluable help in publicising and evaluating the ments, for their invaluable help in publicising and evaluating the
intervention, Mrs Francine Ducharme for help in designing it, participating public and private clinics, physicians and nurses for complying with the unusual procedures, the many persons who volunteered to help run the special immunisation sessions, Dr Jean Vincelette of the Centre hospitalier universitaire de Montréal for the serological testing, and Dr Richard Massé for his keen support as head of the Infectious Diseases Unit. We also thank two reviewers for their helpful comments.

Funding: funding for the intervention and its evaluation was provided by SmithKline Beecham, through the Québec Ministry of Health and Social Services, which also paid for the vaccine. None of the authors had or has any financial connection with SmithKline Beecham. Conflicts of interest: none. 
1 CDC. Hepatitis A among homosexual men-United States, Canada, and Australia. MMWR Morb Mortal Wkly Rep $1992 ; 41: 155,161-4$.

2 Christenson B, Broström C, Böttiger M, et al. An epidemic outbreak of hepatitis A among homosexual men in Stockholm. Am f Epidemiol 1982;116:599-607.

3 Stokes ML, Ferson MJ, Young LC. Outbreak of hepatitis A among homosexual men in Sydney. Am $\mathcal{F}$ Public Health 1997;87:2039-41.

4 Finton R, Abernathy S, Kaufman B, et al. Hepatitis A vaccination of men who have sex with men-Atlanta, Georgia, 11.

5 Corey L, Holmes KK. Sexual transmission of hepatitis A in homosexual men: Incidence and mechanism. $N$ Engl f Med 1980;302:435-8.

6 Henning KJ, Bell E, Braun J, et al. A community-wide outbreak of hepatitis A: risk factors for infection among homosexual and bisexual men. Am $\mathcal{F}$ Med 1995;99:132-6.

7 Stewart T, Crofts N. An outbreak of hepatitis A among homosexual men in Melbourne. Med f Aust 1993;158:519homos.

8 Desenclos JC, MacLafferty L. Community wide outbreak of hepatitis A linked to children in day care centres and with increased transmission in young adult men in Florida 1988-9. F Epidemiol Community Health 1993;47:269-73.

9 Leentvaar-Kuijpers A, Kool JL, Veugelers PJ, et al. An outbreak of hepatitis A among homosexual men in Amsterdam, 1991-1993. Int f Epidemiol 1995;24:218-22.

10 Sundkvist T, Aitken C, Duckworth G, et al. Outbreak of acute hepatitis A among homosexual men in East London. Scand F Infect Dis 1997;29:211-12.

11 Walsh B, Sundkvist T, Maguire H, et al. Rise in hepatitis A among gay men in the Thames regions 1995 and 1996. Genitourin Med 1996;72:449-50.

12 Newell A, Asboe D, Azadian B. Outbreak of hepatitis A in homosexual men in Riverside. Sex Trans Infect 1998;74: $304-5$
13 Ishida T, Nakamura T, Ajisawa A, et al. Outbreak of hepatitis A virus infection among HIV-1 seropositive men who had sex with men. Fpn f Infect Dis 1999;52:131-2.

14 Hoybye G, Skinhoj P, Hentzer B, et al. An epidemic of acute viral hepatitis in male homosexuals. Etiology and clinical characteristics. Scand F Infect Dis 1980;12:241-4.

15 Allard R, Durand L, Guy M, et al. Hepatitis A in downtown Montréal, Québec, 1990-1992. Can Commun Dis Rep 1995;21:71-6.

16 Werzberger A, Mensch B, Kuter B, et al. A controlled trial of a formalin-inactivated hepatitis A vaccine in healthy children. N Engl f Med 1992;327:453-7.

17 McMahon BJ, Beller M, Williams J, et al. A program to control an outbreak of hepatitis A in Alaska by using an inactivated hepatitis A vaccine. Arch Pediatr Adolesc Med 1996;150:733-9.

18 Averhoff F, Shapiro C, Hyams I, et al. Use of inactivated hepatitis A vaccine to interrupt a communitywide hepatitis A outbreak. In: Interscience conference on antimicrobial agents and chemotherapy (ICAAC). New Orleans: American Society for Microbiology, 1996:176.

19 Craig AS, Moore W, Schaffner W, et al. Use of hepatitis A vaccine to control a communitywide outbreak. Clin Infect Dis 1996;23:911.

20 Prikazsky V, Olear V, Cernoch A, et al. Interruption of an outbreak of hepatitis A in two villages by vaccination. $7 \mathrm{Med}$ Vutbreak of hepatitis $1994 ; 44: 457-9$.

21 Payment P. Antibody levels to selected enteric viruses in a French-Canadian population in the province of Québec (Canada). Immunology Inf Dis 1991;1:317-22.

22 Katz MH, Hsu L, Wong E, et al. Seroprevalence of and risk factors for hepatitis A infection among young homosexual and bisexual men. F Inf Dis 1997;175:1225-9.

23 Bryan JP, Nelson M. Testing for antibody to hepatitis A to decrease the cost of hepatitis A prophylaxis with immune globulin or hepatitis A vaccines. Arch Intern Med 1994;154: g63-8. 